This is the peer reviewed version of the following article: White, C, Wray, J, Whitfield, C. 'A fifty mile round trip to change a lightbulb': An exploratory study of carers' experiences of providing help, care and support to families and friends from a distance. Health Soc Care Community. 2020; 00: 1- 11., which has been published in final form at ttps://doi.org/10.1111/hsc.12988. This article may be used for non-commercial purposes in accordance with Wiley Terms and Conditions for self-archiving.

\title{
"A fifty mile round trip to change a lightbulb": an exploratory study of carers' experiences of providing help, care and support to families and friends from a distance.
}

\begin{abstract}
While the role of carers has been widely investigated, the experiences of those who care from a distance have been little explored, especially in the UK. However, contemporary patterns of family life suggest that this may be a significant experience for many. This exploratory study employed an anonymous online survey, conducted April - November 2017, to collect data about specific issues (experiences, challenges, and satisfactions) faced by carers living at a distance requiring at least one hour's travel time (each way) from the person they support.
\end{abstract}

128 participant responses were analysed. Qualitative (thematic) analysis identified that 'distance carers' carry out multiple care tasks, both when with, and apart from, the person they care for. Distance creates specific challenges for carers who have to work to 'bridge the distance gap' and who cannot 'just drop in' and see the person they support. Distance further exposes carers to emotional, financial and temporal demands. The use of technologies or the availability of a wider support network may support distance carers, and some explore the viability of relocation. However, these potential support strategies were identified as 'fragile' and at risk of breaking down. Despite the challenges identified, distance carers also reported satisfactions derived from supporting their relative/friend. While the numbers of those providing distance care are unknown, this research suggests 
that this is a significant carer group, whose needs should be recognised in health and social care policy, practice and research.

\section{Key words}

Informal Carers; Caring; Distance Care; Support; Family Care; Care Networks

\section{What is known about this topic?}

- Significant support is provided by informal carers; however distance carers are an under-researched group

- Existing research suggests that distance may lead to specific challenges, impacting carers' health, finance, employment and social lives

- Distance care appears an emergent and growing aspect of caring within the UK, and internationally

\section{What this paper adds}

- 'Distance carers' undertake a multiplicity of roles and tasks

- Distance itself does not preclude providing care, however, there are distinct challenges arising from distance

- Distance carers are an important carer group requiring particular consideration and who should not be overlooked within the health and social care policy, practice and research.

\section{Introduction}

Over 1.5 million people in the UK provide significant levels of unpaid care saving the health and social care sectors an estimated $£ 132$ billion annually (Buckner \& Yeandle, 2015). Research has highlighted significant challenges for carers; these include impacts on carers' 
health, psychological wellbeing, employment and finances; difficulties meeting their social, emotional and health needs, and balancing their needs with those of the person supported; time demands which impact on carers' workplace participation, time with family and friends (Carers UK, 2019; King \& Pickard, 2013; Ploeg et al, 2019; Rand \& Malley, 2014; Verik, Medar \& Saks, 2019). Carers undertake significant roles in navigating services, yet experience challenges in accessing support for themselves or the person they support (Rand \& Malley, 2014, Bunn et al., 2017). Recent austerity measures have reduced the availability and quality of services, increasing reliance on unpaid carers (Brimblecombe, Pickard, King \& Knapp, 2018; Malli, Sams, Forrester-Jones, Murphy \& Henwood, 2018).

Carers are a diverse group (Moriarty, Manthorpe \& Cornes, 2015; Larkin, Henwood \& Milne, 2019) in respect of their roles and relationships. While carers have been extensively researched, certain groups, such as older, BAME and LGBT carers have received limited attention (Larkin et al., 2019). A key group whose needs and experiences have also been overlooked are those caring from a distance (Edwards, 2014; Koerin \& Harrigan, 2003; Larkin et al., 2019, Li, Mao, Chi \& Lou, 2019), consequently, there is little data about the number of 'distance carers'. However, this appears a significant group, numerically and in respect of the amount of support provided (Douglas, Mazanec, Lipson \& Leuchtag, 2016; Edwards, 2014; Koerin \& Harrigan, 2003; Metlife, 2004).

Distance caring may arise for multiple reasons, including contemporary patterns of family life; family dispersal due to employment or education; personal choice in response to family dynamics (Dean, Kellie \& Mould, 2014; Kovacs, Possick \& Buchbinder, 2019). A lack of appropriate care provision may lead to people, such as those with learning disabilities or 
mental health issues, being moved out of area, distancing them from support networks (Beadle-Brown, Mansell, Whelton, Hutchinson \& Skidmore, 2006; Killaspy et al., 2009).

The availability of informal care has been associated with the proximity of individuals to their social networks (Fernandez-Carro \& Vlachantoni, 2019; Rodriguez, Minguela Recover \& Camacho Ballestra, 2017); however, many care tasks can be accomplished from a distance, for example, through the use of technologies (Milligan \& Wiles, 2010). Research into distance caring has been conducted primarily within the United States, although recent studies in Germany, Switzerland and China indicate a growing awareness of this phenomenon internationally (Kramer et al., 2017; Li et al., 2019). Such research has chiefly focussed on adult children caring for ageing parents, people living with dementia or cancer (Edwards, 2014; Roff, Martin, Jennings, Parker \& Harmon, 2007; Mazanec, Daly, Ferrell \& Prince-Paul, 2011); it has highlighted the significant levels of support provided by 'distance carers' and specific distance-related challenges. These include costs and time associated with travel, and the emotional and social impacts of distance caring (Douglas et al., 2016; Edwards, 2014; Koerin \& Harrigan, 2003; Manthorpe, 2001; Metlife, 2004).

Distance caring has been underexplored in the UK, although one in five adults live two or more hours away from their parents (Petrie \& Kirkup, 2018), highlighting the potential for caring and distance to become intertwined. Although policy identifies different carer roles (Department of Health and Social Care (DHSC) 2018 a \& b) distance carers are not recognised or defined. Distance is mentioned in the context of supporting individuals' involvement in assessments, planning and review processes, in which it is asserted that 'a family member who lives at a distance and only has occasional contact' is unlikely to be 
suitable for this role (DHSC 2018), suggesting a policy-led assumption that distance carers lack involvement and knowledge of the circumstances of those they support.

\section{Aims}

This exploratory study aimed to further our understanding of 'distance caring' in the UK through the following research questions:

- What are the experiences of people who provide help, care and support to a relative or friend living at a distance?

- What care activities do they undertake?

- What difficulties, challenges, rewards and satisfactions do they experience in caring from a distance?

- What support do they access?

\section{Methods}

\section{Study design}

An online survey methodology was employed. Online research facilitates wide geographic coverage, valuable in an exploratory study, the participation of potentially hard to reach groups (Eysenbach \& Wyatt, 2002; Tates et al., 2009; Walker, 2019), and enables carers, who experience demands on their time, to respond at their convenience (Horrell, Stephens \& Breheny, 2015). This approach assumes access to the internet; a paper questionnaire was therefore available on request.

No formal definition of caring was adopted, in order to facilitate the inclusion of diverse caring experiences, roles and relationships. Carers supporting people in a range of settings, including their own homes, care homes and inpatient units were eligible, acknowledging the 
continuation of informal care in staffed settings (Bigby, Webber \& Bowers, 2015; Dean et al., 2014; Ryan \& McKenna, 2015). The well documented rejection of the label and identity of 'care' and 'caring' for some was acknowledged (Dean et al., 2014; Knowles et al., 2016); instead the terms 'help, care and support' were used, reflecting the diverse ways in which carers may perceive their roles.

Distance, in respect of caring, has been defined in relation to travel time, mileage or self-report (Li et al, 2019). This study adopted the perspective that travel time, rather than physical distance, was likely to be a significant factor for carers, which would vary according to the mode of transport used. Distance was defined as requiring one or more hours travel time (each way) when visiting the person receiving care; this accords with previous studies (Metlife, 2004; Roff et al.,2007).

\section{Survey design}

The survey was developed following a literature review, and checked by three carers (including two distance carers) to ensure relevance and accessibility (INVOLVE, 2016). Closed questions captured demographic information, and open questions explored experiences, roles, challenges, worries and dilemmas. Satisfactions and rewards were also explored, as previous research has been criticised for being overly concerned with the 'burdens' of caring (Brown \& Brown, 2014), although rewards and satisfactions have been reported (Douglas et al., 2016; Lloyd, Patterson \& Muers, 2016; MacBride, Miller \& Dewar, 2017). Participants were also asked whether anyone else provided support, and about use of technologies.

\section{Data collection}


A purposive volunteer sample was recruited. Details about the research were posted on Twitter, with carer and non-carer organisations followed; carers'/young adult carers' organisations were contacted via email and asked to publicise the study; posters were displayed in the locality in which the research was conducted.

Individuals were invited to participate if they:

- Were aged 18 years or over

- Cared for another adult

- Both lived in the UK, separated by distances necessitating travel time of one or more hours (each way) when visiting

- Had provided care and support from a distance during the previous two years.

The survey was available via Bristol Online Survey (BOS), and by post, from April to November 2017.

\section{Data analysis}

Closed questions, or those with pre-defined responses, were analysed using BOS software which enables the reporting of descriptive statistics. Thematic analysis was conducted on text based responses (Braun \& Clarke, 2006). All three researchers read this data independently, using an inductive approach to identify initial codes within the data. These were reviewed to identify differences and commonalities, leading to a revised coding framework and the development and refinement of themes (Braun \& Clarke, 2006).

\section{Ethics}


Ethical approval was obtained from the University of [name currently anonymised for review] Ethics Committee. A Data Management Plan was submitted, detailing the storage and disposal of data, in accordance with UK General Data Protection Regulation.

Study information was provided at the beginning of the survey, which was completed anonymously. Written consent was not sought; completion was taken to signify consent. Participants were asked to indicate whether they agreed to the use of anonymised quotes. As reflecting on caring experiences may have been upsetting for some, and online methods do not enable monitoring of participant wellbeing (Chiasson et al., 2006), an information section detailing sources of support was included.

\section{Findings}

128 surveys were analysed (11 were excluded as they were incomplete or participants were outside the UK).

Demographic details of participants and those they supported are shown in Tables 1 and 2 . A substantial majority of participants were women (89\%), with those aged 51-60 the largest group. Consistent with UK data on family carers (Petrie and Kirkup, 2018) the majority supported parents, although those caring for siblings and adult children were also represented. Almost two-thirds were in employment or education. Thus a substantial proportion of the sample appeared to represent the 'sandwich generation' who juggle supporting parents/grandparents, children/grandchildren, and employment, and reflects the trend that most of those providing care outside the home are women in mid-life (Carers UK, 2019; Norman \& Purdham 2013; Vlachantoni, Evandrou, Falkington \& Gomez-Leon, 2019). 
Travel times reported ranged from 1-2 hours to 10 or more (Table 3). Analysis identified five main themes, and subthemes, detailed in Table 4. Illustrative quotes are included; these identify the participant number; relationship to the person supported; distance travelled.

\section{1) A multiplicity of roles}

Despite living at a distance, carers undertook a wide range of tasks, outlined in Table 5 and illustrated below:

I have a good working relationship with the home managers and help to ensure the care package is always being provided. I help to ensure all health needs are being met and attend all hospital appointments to provide history and continuity for her, I visit and she visits us to ensure wider family contact. I provide practical care when I visit I ensure her leisure time is full and she has what she needs to be sensory stimulated. She may live away from us but I am fully involved with all care planning and every aspect of her care needs, but care workers provide it. (C18, son/daughter, 1-2 hours)

Some tasks, such as personal care and housework, require carers to be with the care-recipient, and therefore to travel. Others, such as spending time together, acting as a care manager and shopping, can be conducted proximally or from afar, in some instances supported by technologies.

\section{2) Challenges imposed by distance}

\section{'You can't just pop in'.}

Distance carers could not readily visit their relative/friend. Not being able to see the person and their environment made it difficult for carers to assess their safety and wellbeing. Instead, they relied on others' accounts. This was difficult if clear, trusted communication with other carers was lacking, their relative/friend had memory problems, or was perceived to minimise difficulties to spare their carer anxiety. Accordingly, it could be difficult for carers to gauge the seriousness of situations and the actions required:

Not being able to see my mother makes it difficult for me to see how she is doing, though I can usually tell when I speak to her on the phone if she is 
'down' but she has ways of trying to hide this from us - which is easier at a distance. (C23, parent, 1-2 hours)

In this context, responding to emergencies was a challenge and source of anxiety. Equally, addressing small, non-emergency, matters was difficult; one participant highlighted the potential for a '50 mile round trip to change a lightbulb' (C10, sibling, 1-2 hours).

\section{Bridging the distance gap}

Carers worked to narrow this gap through frequent phone calls and visits. This could involve considerable travel time, and interruptions to work or studies:

If she needs me to attend appointments with her, then I have to arrange time off work. (C23, parent, 1-2 hours)

In this context, the support of employers, and the ability to work flexibly or from their own or relative/friends' home was valued:

When I needed to visit my father in hospital my employer was flexible about me starting and leaving work a bit earlier so that I wasn't driving back tired and in the dark so much. (C21, parents, 1-2 hours)

However, others experienced a lack of support from employers.

Distance influenced visiting patterns, meaning visits could be less frequent than desired, and intense; this was perceived as disadvantageous:

Main difficulty is in frequency of visits. Would rather do little and often so can make bigger more consistent impact rather than come in like a whirlwind and try to do everything fast. Hard to coordinate and overwhelming for them. (C82, 'other' relative, 1-2 hours)

\section{Location}

Living in different geographic areas to those supported presented a further challenge.

Where services worked within tightly defined locality boundaries, support for distance carers could be impacted: 
Mum used to come to stay in [carers' area] but Local Authority homes will not place anyone outside their authority for respite. She can go into one near her and see no-one all week but that's not in her best interests. (C75, parent, 1-2 hours)

I'm not entitled to any carer support cos I don't live in her area and the carers org I was referred to after carers' assessment doesn't accept ppl from out of area. (C91, sibling, 3-4 hours)

Participants also highlighted a lack of recognition of distance caring from paid carers and agencies:

Professionals not believing me 'How can you say she's having these problems when you're not there?' (C3, parent, 5+ hours)

Some carers themselves appeared ambivalent about the status of their role and whether they were 'proper' carers, in contrast with those living closer or with the person.

\section{3) Impacts of distance on carers}

\section{Emotional demands}

Participants frequently reported experiencing worry and anxiety 'like a background hum in my life' (C75, parent, 1-2 hours). Sources of anxiety included concerns about their relative/friend's health, wellbeing and safety; their ability to respond in an emergency; not being able to see the person. They also reported guilt for 'not being there' and feeling torn between the needs of family at home and their relative/friend:

Worry about how far away Mum is. Difficult leaving her knowing she lives alone and is vulnerable. Worry about the future. Worry that sometimes appointments and shopping take up more time than just being with Mum. (C4, parent, 1-2 hours)

Non practical worries are that I feel guilty for not being there - "everyone else has family in the village" and not being able to pop in and support her daily. (C37, parent, 4-5 hours)

\section{Financial demands}


Bridging the distance gap had financial costs, including costs of travel, phone bills, and in some cases lost earnings, due to the impact on employment:

Not being able to work as many hours as are available to me due to needing to take time to resolve issues and complete general day to day organisation of her life, which is much more complicated and time consuming than if I was local. (C9, parent, 1-2 hours)

For some, these costs were not experienced as problematic, and some received recompense from the person they supported. For others, however, the costs were hard felt:

I spend around $£ 100-£ 150$ a month on visiting and related costs, my mileage is through the roof ( $32 \mathrm{k}$ miles in 12 months) and I am having to have my car serviced twice a year as a result. (C101, parent, 2-3 hours)

\section{Temporal demands}

Distance carers invested time in travelling to support their relative/friend; this travel could be tiring and stressful. Participants reported juggling needs and commitments across two places, supporting their relative/friend, alongside meeting commitments to their own family, home, work and social lives.

\section{4) Strategies that support distance carers}

\section{The use of technologies}

Many carers used technologies; these included 'specialist' care oriented technologies, such as sensors, monitors and alarms, and online forums for information and support. They also frequently used 'everyday' technologies to achieve practical tasks (such as shopping or banking) remotely; keep in touch; monitor safety.

Barriers to use were also identified. Some reported that their relative/friend was unwilling or unable to use technologies:

We mostly speak by landline as they don't like new technology. My mother has found online shopping unsatisfactory - what she's ordered and what's 
been delivered hasn't matched so that's the end of that! (C105, parents, $5+$ hours)

Hearing problems could impede communication and contact by phone. Further, the adoption and ongoing use of technologies could be prevented or made more difficult by memory loss; carers recommended early adoption to facilitate learning. Some reported being unable to use technologies to contact the person they supported, due to a lack of the necessary infrastructure or assistance. This affected those caring for relatives/friends living in their own homes and care homes:

[Need] someone who would help her 'facetime' so she could see and hear me and I could see her expression. (C38, son/daughter, 2-3 hours)

It would be nice to be able to Skype my Mum as she no longer talks in the telephone but there is no facility for that. (C27, 'other' relative, 2-3 hours)

Perhaps as a result of the barriers identified, some reported that they used no technologies to support caring.

\section{Being part of a care network}

Many distance carers (92\%) were part of care networks. Some shared caring with other family members. Participants reported supportive relationships among families, but also tensions and difficulties in navigating and negotiating roles:

My sister shares equal responsibility with me and we are able to support each other. (C19, parent, 5+ hours)

Tension with other siblings who are unprepared to help despite living nearer. (C116, sibling, 3-4 hours)

Neighbours and friends also provided valuable support undertaking roles such as visiting, taking the person out, providing practical support, acting as 'my ears and eyes' (C87, son/daughter, 1-2 hours). However, there was potential for disagreements, and some neighbours were reportedly ageing, in poor health, or were perceived as unable to cope 
with conditions such as dementia, suggesting that this support might break down or be disrupted.

Support was also provided by paid carers. Respondents highlighted the importance of trust in care providers (which was not universally present). The factors that facilitated such trust were not clear, however, responses suggest that good communication and information sharing may contribute:

We have a good relationship with the care providers, I trust them, they are good with his healthcare needs. All this helps. Communication is good. (C16, son/daughter, 1-2 hours)

Some also highlighted the importance, and difficulty, of identifying reliable and trustworthy people to carry out home repairs and in overseeing their work from a distance:

It is the less regular things that create more work and stress. For example finding a trusted trader that will not only do the job but interact with my relative properly and treat them with respect and not leave a mess afterwards; make sure everything is working properly. (C48, 'other' relative, 3-4 hours)

\section{Relocation}

Relocation of the carer, or person they supported, to the same locality, was a strategy adopted or considered by some:

Life has hugely improved in the last 9 months since dad has moved into care in my home town 15 mins down the road. Both he and I now have a much better quality of life and have regained an enjoyable father/daughter relationship. (C41, parent, 5+ hours)

However, there were dilemmas associated with this option:

Wish she was closer as I feel it would be simpler \& could be part of her life a bit more but she has lived there a long time and it would be unsettling/possibly unfair to move her (Carer 83, sibling, 1-2 hours).

\section{5) Rewards and satisfactions}


Participants reported satisfactions in their relationships, as well as enjoyment in the time spent with their relative/friend:

I'm very pleased to be helping and getting closer to my mum when she most needs me. We do have some very affectionate and funny times. (C27, 'other' relative, 2-3 hours)

The ability to reciprocate and honour support given in the past provided satisfaction, as did supporting the person to live their chosen lifestyle, such as remaining in their own home:

Just to know he's ok and looked after without being put in a home or having carers. Helping to keep him as independent as possible is massively rewarding and the reason I juggle so much. (C64, parent, 1-2 hours)

In contrast, some experienced difficult relationships with those they supported, identified no satisfactions, or articulated their role in terms of duty.

\section{Discussion}

This study explored the experiences of distance carers. In common with the broader carer population, they undertook a range of roles and reported experiencing worry, anxiety, and impacts in respect of their employment, finances and the need to juggle multiple roles, as well as identifying satisfactions and rewards. The underlying reasons for these impacts included 'distance related' factors, such as the costs of travelling long distances and the anxieties associated with anticipating how to respond to future emergencies from a distance. The findings further our understanding of the unique challenges imposed when the need to navigate distance is an element of caring. The inability to readily 'pop in' and see the person supported represented a significant concern, in which carers could not easily see how the person was managing (and where those supported could more readily conceal difficulties and episodes of ill-health). This necessitated a reliance on proxy accounts, however, proxy informants were not always perceived as reliable, contributing to carers' 
anxiety. The findings also highlighted the time, money and work required by distance carers to enable them to bridge the 'distance gap' through travel, arranging visits, making phone calls, and in some cases on a more permanent basis through relocation. The difficulties created by living in a different locality to the person supported meant that some carers could not access carers' support services. Indeed in England, the guidance to the Care Act 2014 stipulates that local authorities must:

Establish and maintain a service for providing people in its area with information and advice relating to care and support for adults and support for carers (DHSC, 2018, emphasis added).

Therefore in a context of austerity, increasing need for services, and consequent unmet needs (Moriarty et al., 2015) those whose caring roles cross locality boundaries may find themselves a low priority at best, both in the area they live, and in that of the person they support, such that they risk becoming 'hidden carers'.

Although important, distance is an abstract and arbitrary concept, as illustrated by the different measures adopted across studies. In this research we defined distance as requiring travel time of at least one hour when visiting the person supported. However, it appears that some of our findings are also pertinent to other carers who spend time apart from the person they support, regardless of distance, for example while at work, using respite services, following a move into residential care. Common needs for all such carers are to be able to stay in contact with the person they support, and to feel assured that they are receiving good care and support (if required); use of paid carers and technologies have the potential address these needs. Everyday technologies can enable carers to keep in touch with the person they support, however, participants experienced challenges in using these 
when support staff lacked access to the relevant technologies or the time and skills to use them (Challenging Behaviours Foundation/Mencap, 2016; Zamir, Hennessy, Taylor \& Jones, 2018). These findings call into question the extent to which enabling individuals to maintain contact with their support network is perceived as a valid and important element of care and support, and a priority for care providers and funders, highlighting a need to address these for distance carers, and other carers who spend time apart from those they support. The findings also pointed to the importance of trust and positive communication in enabling carers to feel confident that their relative/friend is well supported in their absence, and that information provided is accurate, timely and reliable. The facilitators and barriers to trust and effective communication with paid carers are areas in which further research is needed, however the importance of staff understanding what issues they should contact carers about, and acting on these understandings, appears important, as does staff continuity, joint decision making and attention to 'little things' that indicate positive care delivery and valuing of the person (Bigby et al., 2015; McSwiggan et al., 2017: Ryan \& McKenna, 2015). The study explored strategies used by distance carers. Being part of a care network, the use of technologies, and relocation were all employed or considered. Although these could provide valuable support, difficulties and challenges were also identified, including disagreement and relationship strain among families in navigating and negotiating care roles (Edwards, 2014; Roff et al., 2007; Tatangelo, McCabe, Macleod \& Konis, 2018); time demands for carers in sourcing and learning to use new technologies (Arntzen, Holthe \& Jentolt, 2016); difficulties in relocating to new areas (Marsland, White \& Manthorpe, 2019). Thus, they appear 'fragile solutions', which risk breaking down or becoming unacceptable to carers or those receiving support, highlighting the precariousness of the distance caring role, 
the changing landscape of caring, and the need for the adoption of new strategies to maintain caring.

The fragility of these strategies further highlights the need for effective support for distance carers, who, to date, have largely been ignored within policy and research. Research frequently lacks specification of the distances between carers and those they support, and in common with health and social care policy appears to assume that they live together or in close proximity. However, some recent research has included the perspectives of distance carers within broader research questions (Bunn et al, 2017; Davies et al, 2019) or delineated the distances between carers and those they support (Vick, Ornstein, Szanton, Dy \& Wolff, 2019; Washington et al, 2019; Wolff et al, 2018), highlighting diversity among carers, the geographies of care, challenges experienced and potential solutions. Further, research reviewed by Spann et al (2019) underscored the importance of distance among working carers' who have to navigate distances between their workplace, their own home and that of the person they support, further highlighting the importance of interrogating geographies of care. Attention to the geographies, relationships and living arrangements of carers within future research will provide a more person-centred, holistic policy and practice focus that better reflects the needs of the care dyad (Heli, Rauhala \& Fagerström, 2019).

\section{Limitations and future research}

This was an exploratory study which examined an under-researched aspect of caring. The methodology employed enabled a diverse range of carers to provide an overview of their experiences. Methodologies which enable the collection of more in-depth accounts of carers' experiences are required to complement and expand this data. 
Distance carers constitute a largely hidden group, who may not identify with the term 'carer' or be eligible for support from local carer agencies. Therefore, they are a potentially difficult group from which to recruit. Social media was used in recruitment, and was supplemented (as with Morris, 2013; Walker, 2017) by making direct contact with supporting agencies. However, use of social media relied on carers' use, and trust, of this source of recruitment, and the success of contacting agencies relied on their accessibility and responsiveness to distance carers. Male carers and those from BAME communities were poorly represented, notwithstanding attempts to target these populations. Thus the perspectives reported here may not provide a full picture of distance carers' experiences. A recent online survey by Watts \& Cavaye (2018) which also used social media and carers' organisations for recruitment achieved similar proportions of male/female participants to this study, suggesting that these may not be optimal recruitment methods to ensure participant diversity, and that additional approaches may be needed in future studies.

This research was solely concerned with the experiences of carers. However, the perspectives of people living at a distance from members of their support network, their concerns (if any) and the coping strategies they employ (c.f. Mitchell, 2019) are also important for inclusion in future research concerned with distance and care.

This exploratory study suggests further areas for future research. These include; exploring the concept of distance, how this influences carer experiences and interactions with others; the scale of the distance carer population; distance carers' perceptions of themselves as carers, and the ways in which health and social care practitioners support (or militate against) recognition of their caring roles; how carers are supported to maintain contact when apart from the person they support. Further, research to compare carers' experiences 
according to variations in distance/proximity is also of value. To date, comparisons of the differences between proximal and distance carers is made difficult due to the lack of focus on, and acknowledgment of, distance in most carer focussed research. Comparisons between carers separated by those they care for by varied geographic distances is also a valuable area for exploration; however the data collected in this study did not enable such comparisons to readily be made. There appear to be complex interconnections between distance and other aspects of carers' circumstances such as frequency of travel, flexibility of employment, and financial resources, rather than simple linear relationships. Future research into the effects of different distances on the situations and experiences of carers, need to take into account such factors.

\section{Conclusions}

Providing help, care and support at a distance is a distinct, but often neglected, area of carer experience. This study has identified some key challenges experienced by this group. Distance carers appear to have had a low profile, which is reflected in carers' observations that services do not recognise distance carers or meet their needs, and their own ambivalence about the legitimacy of claiming a carer identity. The UK Carers' Action Plan (Department of Health and Social Care, 2018b, p8) recognises the diversity of caring roles, and attests that 'there is no such thing as a "typical carer"'; it is important that policy, practice and research extend this acknowledgement of carer diversity to include those who contend with the challenges of distance. 


\section{References}

Arntzen, C., Holthe, T., \& Jentolt, R. (2016). Tracing the successful incorporation of assistive technology into everyday life for younger people with dementia and family carers.

Dementia, 15, 646-662. https://doi.org/10.1177/1471301214532263

Beadle-Brown, J., Mansell, J., Whelton, B., Hutchinson, A., \& Skidmore, C. (2006). Too far to go: Out of area placements for people with intellectual disabilities. Tizard Learning Disability Review, 11, 24-34. https://doi.org/10.1108/13595474200600005

Bigby, C., Webber, R., \& Bowers, B. (2015). Sibling roles in the lives of older group home residents with intellectual disability: Working with staff to safeguard wellbeing. Australian Social Work, 68, 453-468. https://doi.org/10.1191/1478088706qp063oa

Braun, V., \& Clarke V. (2006). Using thematic analysis in psychology. Qualitative Research in Psychology, 3, 77-101. https://doi.org/10.1191/1478088706qp063oa

Brimblecombe, N., Pickard, L., King, L. \& Knapp, M. (2018). Barriers to receipt of social care services for working carers and the people they care for in times of austerity. Journal of Social Policy, 47, 215-233. doi:10.1017/S0047279417000277

Brown, R. M., \& Brown, S. L. (2014). Informal caregiving: a reappraisal of effects on caregivers. Social Issues and Policy Review, 8, 74-102. https://doi.org/10.1111/sipr.12002

Buckner, L., \& Yeandle, S. (2015). Valuing Carers 2015: The rising value of carers' support. Carers UK, The University of Sheffield, University of Leeds, Centre for International Research on Care, Labour \& Equalities. Retrieved from https://www.carersuk.org/for-professionals/policy/policy-library/valuing-carers-2015 Bunn, L., Burn, A-M., Robinson, L., Poole, M., Rait, G., Brayne, C., Schoeman, J., Norton, S. \& Goodman, C. (2019). Healthcare organisation and delivery for people with dementia and comorbidity: A qualitative study exploring the views of patients, carers and professionals. BMJ Open, 7:e013067. doi:10.1136/bmjopen-2016-013067

Carers UK. (2018). State of caring 2018. London: Carers UK. Retrieved from https://www.carersuk.org/images/Downloads/SoC2018/State-of-Caring-report-2018.pdf 
Carers UK. (2019). Facts about carers: Policy briefing. London: Carers UK. Retrieved from https://www.carersuk.org/for-professionals/policy/policy-library/facts-about-carers-2019

Challenging Behaviour Foundation/Mencap. (2016). Keeping in touch with home: How to help children and young people with learning disabilities and their families keep in touch when they are living away from home. Chatham: Challenging Behaviour Foundation. Retrieved from

http://pavingtheway.works/project/wp-content/uploads/2016/07/Keeping-in-touch-with-h ome-web-version.pdf

Chiasson, M. A., Parsons, J. T., Tesoriero, J. M., Carbello-Dieguez, A., Hirshfield, S., \& Remien, R. H. (2006). HIV Behavioural Research Online. Journal of Urban Health: Bulletin of the New York Academy of Medicine, 83, 73-85. https://doi.org/10.1007/s11524-005-9008-3

Davies, N., Illiffe, S., Hopwood, J., Walker, N., Ross, J., Rait, G. \& Walters, K. (2019). The key aspects of online support that older family carers of people with dementia want at the end of life: A qualitative study. Aging \& Mental Health, DOI:10.1080/13607863.2019.1642299 Dean, D., Kellie, J., \& Mould, P. (2014). From pushchairs to wheelchairs: Understanding tensions in family decision making through the experiences of adult children caring for ageing parents. Journal of Marketing Management, 30, 1703-1721.

https://doi.org/10.1080/0267257X.2014.934268

Department of Health and Social Care (2018a) Carers Action Plan 2018-2020: Supporting carers today. London: Department of Health and Social Care. Retrieved from https://assets.publishing.service.gov.uk/government/uploads/system/uploads/attachment data/file/713781/carers-action-plan-2018-2020.pdf

Department of Health and Social Care (2018b) Care and support statutory guidance. London: Department of Health and Social Care. Retrieved from

https://www.gov.uk/government/publications/care-act-statutory-guidance/care-and-suppo $\underline{\text { rt-statutory-guidance }}$

Douglas, S. L., Mazanec, P., Lipson, A., \& Leuchtag, M. (2016). Distance caregiving a family member with cancer: A review of the literature on distance caregiving and 
recommendations for future research. World Journal of Clinical Oncology, 7, 214- 219. DOI: 10.5306/wjco.v7.i2.214

Edwards, M. (2014). Distance caregivers of people with Alzheimer's disease and related dementia: A phenomenological study. British Journal of Occupational Therapy, 77, 174-180. https://doi.org/10.4276/030802214X13968769798719

Eysenbach, G., \& Wyatt, J. (2002). Using the internet for surveys and health research. Journal of Medical Internet Research 4(2) E13. doi:10.2196/jmir.4.2.e13

Fernandez-Carro, C., \& Vlachantoni, A. (2019). The role of social networks in using home care by older people across Continental Europe. Health and Social Care in the Community, 0, 1-17. https://doi.org/10.1111/hsc.12711

Heli, V.R., Rauhala, A. and Fagerström, L. (2019). Person-centered home-based rehabilitation for persons with Parkinson's disease: A scoping review. International Journal of Nursing Studies, 103395. https://doi.org/10.1016/i.ijnurstu.2019.103395

Horrell, B., Stephens, C., \& Breheny, M. (2015). Capability to care: Supporting the health of informal caregivers for older people. Health Psychology, 34, 339-348.

http://dx.doi.org/10.1037/hea0000144

INVOLVE, NIHR. (2016). Briefing note three: Why involve members of the public in research. Retrieved from

http://www.invo.org.uk/posttyperesource/why-should-members-of-the-public-be-involvedin-research/

Killaspy, H., Rambarran, D., Harden, C., Fearon, D., Caren, G., \& McClinton, K. (2009). A comparison of service users placed out of their local area and local rehabilitation service users. Journal of Mental Health, 18, 111-120. https://doi.org/10.1080/09638230701879235 King, D., \& Pickard, L. (2013). When is a carer's employment at risk? Longitudinal analysis of unpaid care and employment in midlife in England. Health and Social Care in the Community 21, 303-314. https://doi.org/10.1111/hsc.12018 
Knowles, S., Combs, R., Kirk, S., Griffiths, M., Patel, N., \& Sanders, C. (2016). Hidden caring, hidden carers? Exploring the experiences of carers for people with long-term conditions. Health and Social Care in the Community 24, 203-213. https://doi.org/10.1111/hsc.12207

Koerin, B. B., \& Harrigan, M. P. (2003). P.S. I love you: Long-distance caregiving. Journal of Gernontological Social Work, 40 (1/2) 63-81. https://doi.org/10.1300/J083v40n01_05

Kovacs, T., Possick, C., \& Buchbinder, E. (2019). Experiencing the relationship with a sibling coping with mental health problems: Dilemmas of connection, communication, and role. Health and Social Care in the Community, 0(0), 1-8. https://doi.org/10.1111/hsc.12761

Kramer, B., Franke, A., Otto, U., Bishofberger, H., Kunz, H., \& Kindl, M. (2017). Distance care: Challenges and potentials beyond national distances and international boundaries. Innovation in Aging, 1(supplement 1), 1108-1109. https://doi.org/10.1093/geroni/igx004.4060 Larkin, M., Henwood, M., \& Milne, A. (2019). Carer-related research and knowledge: Findings from a scoping review. Health and Social Care in the Community, 27, 55-67. https://doi.org/10.1111/hsc.12586

Li, M., Mao, W., Chi, I. and Lou, V. W. Q. (2019). Geographical proximity and depressive symptoms among adult child caregivers: social support as a moderator. Aging and Mental Health, 23, 205-213.

Lloyd, J., Patterson. T., \& Muers, J. (2016). The positive aspects of caregiving in dementia: A critical review of the qualitative literature. Dementia, 15, 1534-1561.

https://doi.org/10.1177/1471301214564792

MacBride, T., Miller, E., \& Dewar, B. (2017). “I know who I am; the real me, and that will come back": The importance of relational practice in improving outcomes for carers of people with dementia. IIIness, Crisis and Loss, 0(0) 1-22.

https://doi.org/10.1177/1054137317700061

Malli, M. A., Sams, L., Forrester-Jones, R., Murphy, G. \& Henwood, M. (2018) Austerity and the lives of people with learning disabilities. A thematic synthesis of current literature. Disability and Society, 33, 1412-1435. https://doi.org/10.1080/09687599.2018.1497950 
Manthorpe, J. (2001). Caring at a distance: Learning and practice issues. Social Work Education, 20(5), 593-602. https://doi.org/10.1080/02615470120075109

Marsland, D., White, C., \& Manthorpe, J. (2019). The continuity of social care when moving across regional boundaries. Journal of Social Work, 19(5) 557-577.

https://doi.org/10.1177/1468017318762268

Mazanec, P., Daly, B.J., Ferrell, B.R., \& Prince-Paul, M. (2011). Lack of communication and control: Experiences of distance caregivers of parents with advanced cancer. Oncology Nursing Forum, 38, 307-313. doi: 10.1188/11.ONF.307-313

McSwiggan, L. C., Marston, J., Campbell, M., Kelly, T. B., \& Kroll, T. (2017).

Information-sharing with respite care services for older adults: A qualitative exploration of carers' experiences. Health and Social Care in the Community, 25, 1404-1415.

https://doi.org/10.1111/hsc.12440

MetLife (2004). The MetLife market survey of nursing home and home care costs. Westport, CT: MetLife Mature Market Institute.

Milligan, C., \& Wiles, J. (2010). Landscapes of care. Progress in Human Geography, 34, 736-754. https://doi.org/10.1177/0309132510364556

Mitchell, W. (2019) What alone feels like.

https://whichmeamitoday.wordpress.com/2019/02/26/what-alone-feels-like/ Accessed $7^{\text {th }}$ March 2019.

Moriarty, J., Manthorpe, J. \& Cornes, M. (2015). Reaching out or missing out: Approaches to outreach with family carers in social care organisations. Health and Social Care in the Community, 23, 42-50. doi: 10.1111/hsc.12119

Morris, R. (2013). 'Unjust, inhumane and highly inaccurate': The impact of changes to disability benefits and services - social media as a tool in research and activism. Disability \& Society, 28, 724-728. https://doi.org/10.1080/09687599.2013.808093

Norman, P. \& Purdam, K. (2013). Unpaid caring within and outside the carer's home in England and Wales. Population, Space and Place, 19, 15 - 31.

https://doi.org/10.1002/psp.1702 
Petrie, K., \& Kirkup, J. (2018). Caring for carers: The lives of family carers in the UK. London: Social Market Foundation.

Ploeg, J., Northwood, M., Duggleby, W., McAiney, C. A., Chambers, T., Peacock, S. \& Fisher, K. (2019). Caregivers of older adults with dementia and multiple chronic conditions:

Exploring their experiences with significant changes. Dementia, 0, 1-20. DOI:

$10.1177 / 1471301219834423$

Rand, S. \& Malley, J. (2014). Carers' quality of life and experiences of adult social care support in England. Health and Social Care in the Community, 22, 375-385.

\section{https://doi.org/10.1111/hsc.12089}

Rodríguez, M., Minguela Recover, M. Á., \& Camacho Ballesta, J. A. (2017). The importance of the size of the social network and residential proximity in the reception of informal care in the European Union. European Journal of Social Work, 21, 53-664. https://doi.org/10.1080 /13691457.2017.1320523

Roff, L. L., Martin, S. S., Jennings, L. K., Parker, M. W., \& Harmon, D. K. (2007). Long distance parental caregivers' experiences with siblings: A qualitative study. Qualitative Social Work, 6, 315-334. https://doi.org/10.1177/1473325007080404

Ryan, A. A., \& McKenna, H. (2015). 'It's the little things that count': Families' experiences of roles, relationships and quality of care in rural nursing homes. International Journal of Older People Nursing 10, 38-47. https://doi.org/10.1111/opn.12052

Spann, A., Vicente, J., Allard, C., Hawley, M., Spreeuwenberg, M., \& de Witte, L. (2019).

Challenges of combining work and unpaid care, and solutions: A scoping review. Health and Social Care in the Community, 00, 1-17. DOI: 10.1111/hsc.12912

Tatangelo, G., McCabe, M., Macleod, A., \& Konis, A. (2018). I just can't please them all and stay sane: Adult caregivers' experiences of family dynamics in care-giving for a parent with dementia in Australia. Health and Social Care in the Community, 26, e370-e377. https://doi.org/10.1111/hsc.12534

Tates, K., Zwaanswijk, M., Otten, R., van Dulmen, S., Hoogerbrugge, P. M., Kamps, W. A., \& Bensing, J. M. (2009). Online focus groups as a tool to collect data in hard-to-include 
populations: examples from paediatric oncology. BMC Medical Research Methodology, 9(1), 15. doi: 10.1186/1471-2288-9-15

Verik, M., Medar, M. \& Saks, K. (2019). Informal caregivers' experiences of caring for persons with dementia in Estonia: A narrative study. Health and Social Care in the Community, 00, 1-8. DOI: 10.1111/hsc.12877

Vick, J. B., Ornstein, K. A., Szanton, S. L., Dy, S. M. \& Wolff. (2019). Does caregiving strain increase as patients with and without dementia approach the end of life? Journal of Pain Management, 57, 199-208. https://doi.org/10.1016/j.jpainsymman.2018.11.004

Vlachantoni, A., Evandrou, M., Falkingham, J., \& Gomez-Leon, M. (2019). Caught in the middle in mid-life: Provision of care across multiple generations. Ageing and Society, 0(0), 1-21. doi:10.1017/S0144686X19000047

Walker, E. (2019). 'There's no pill to help you deal with the guilt and shame': Contemporary experiences of HIV in the United Kingdom. Health, 23, 97-113.

https://doi.org/10.1177/1363459317739436

Washington, K. T., Parker Oliver, D., Smith, J. B., Kruse, R. L., Meghani, S. H. \& Demiris, G. (2019). A comparison of rural and urban hospice family caregivers' cancer pain knowledge and experience. Journal of Pain Management, 58, 685-689.

https://doi.org/10.1016/j.jpainsymman.2019.07.010

Watts, J. H. \& Cavaye, J. (2018). Being a former carer: Impacts on health and well-being. IIIness, Crisis and Loss, 26, 330-345. https://doi.org/10.1177/1054137316679992

Wolff, J. L., Mulcahy, J., Huang, J., Roth, D. L., Covinsky, K., \& Kasper, J. D. (2018). Family caregivers of older adults, 1999-2015: Trends in characteristics, circumstances, and role-related appraisal. The Gerontologist, 58, 1021-1032.

https://doi.org/10.1093/geront/gnx093

Zamir, S., Hennessy, C. H., Taylor, A. H. \& Jones, R. B. (2018). Video-calls to reduce loneliness and social isolation within care environments for older people: An implementation study using collaborative action research, BMC Geriatrics, 18:62. doi: 10.1186/s12877-018-0746-y 
TABLES

Table 1: Demographic details of the participants (\% rounded, total number of responses $n=x$ )

\begin{tabular}{|c|c|c|}
\hline Characteristic & Categories & Respondent \% / no. \\
\hline \multirow[t]{3}{*}{ Gender ( $n=128)$} & Male & $10 \%(13)$ \\
\hline & Female & $89 \%(114)$ \\
\hline & Prefer not to say & $1 \%(1)$ \\
\hline \multirow[t]{3}{*}{ Ethnicity (n = 128) } & White British & $89 \%(114)$ \\
\hline & BAME & $9 \%(12)$ \\
\hline & Prefer not to say & $2 \%(2)$ \\
\hline \multirow[t]{6}{*}{ Age ranges ( $n=115$ ) } & $21-30$ & $7 \%(8)$ \\
\hline & $31-40$ & $10 \%(11)$ \\
\hline & $41-50$ & $15 \%(17)$ \\
\hline & $51-60$ & $47 \%(55)$ \\
\hline & $61-70$ & $18 \%(21)$ \\
\hline & $71-80$ & $3 \%(3)$ \\
\hline \multirow[t]{11}{*}{ Geographic location ( $n=119)$} & NE England & $4 \%(5)$ \\
\hline & NW England & $9 \%(11)$ \\
\hline & Yorks \& Humber & $16 \%(21)$ \\
\hline & The Midlands & $11 \%(16)$ \\
\hline & London & $11 \%(14)$ \\
\hline & SE England & $16 \%(20)$ \\
\hline & SW England & $8 \%(10)$ \\
\hline & East of England & $8 \%(10)$ \\
\hline & Scotland & $9 \%(11)$ \\
\hline & Wales & $6 \%(8)$ \\
\hline & Northern Ireland & $2 \%(2)$ \\
\hline \multirow[t]{3}{*}{ Respondent status ( $n=128$ ) } & F/T work & $35 \%(45)$ \\
\hline & $\mathrm{P} / \mathrm{T}$ work & $26 \%(33)$ \\
\hline & Student / training & $6 \%(8)$ \\
\hline
\end{tabular}




\begin{tabular}{|l|l|l|}
\hline & Retired & $11 \%(14)$ \\
\hline & Not in paid work & $9 \%(11)$ \\
\hline & Other & $13 \%(17)$ \\
\hline $\begin{array}{l}\text { Relationship to person they support } \\
\text { (n=128) }\end{array}$ & Parent & $57 \%(73)$ \\
\hline & Son / daughter & $13 \%(17)$ \\
\hline & Sister/brother & $12 \%(15)$ \\
\hline & Family member (not listed) & $10 \%(13)$ \\
\hline & Friend & $4 \%(5)$ \\
\hline & Other & $4 \%(5)$ \\
\hline
\end{tabular}

Table 2: Characteristics of the person supported (\% rounded, total number of responses $n=x$ )

\begin{tabular}{|c|c|c|}
\hline Characteristic & Categories & Person supported \% / no. \\
\hline \multirow[t]{3}{*}{ Gender $(n=120)$} & Male & $32 \%(39)$ \\
\hline & Female & $66 \%(79)$ \\
\hline & Prefer not to say & $2 \%(2)$ \\
\hline \multirow[t]{3}{*}{ Ethnicity $(n=128)$} & White British & $91 \%(116)$ \\
\hline & BAME & $8 \%(10)$ \\
\hline & Prefer not to say & $1 \%(2)$ \\
\hline \multirow[t]{9}{*}{ Age ranges $(n=119)$} & Under 21 & $4 \%(4)$ \\
\hline & $21-30$ & $8 \%(10)$ \\
\hline & $31-40$ & $6 \%(7)$ \\
\hline & $41-50$ & $6 \%(7)$ \\
\hline & $51-60$ & $8 \%(10)$ \\
\hline & $61-70$ & $8 \%(10)$ \\
\hline & $71-80$ & $9 \%(11)$ \\
\hline & $81-90$ & $39 \%(46)$ \\
\hline & $91+$ & $12 \%(14)$ \\
\hline \multirow[t]{2}{*}{ Geographic location $(n=128)$} & NE England & $4 \%(6)$ \\
\hline & NW England & $9 \%(11)$ \\
\hline
\end{tabular}




\begin{tabular}{|c|c|c|}
\hline & Yorks \& Humber & $14 \%(18)$ \\
\hline & The Midlands & $6 \%(8)$ \\
\hline & London & $7 \%(9)$ \\
\hline & SE England & $20 \%(26)$ \\
\hline & SW England & $14 \%(18)$ \\
\hline & East of England & $7 \%(9)$ \\
\hline & Scotland & $9 \%(11)$ \\
\hline & Wales & $9 \%(11)$ \\
\hline & Northern Ireland & $1 \%(1)$ \\
\hline \multirow[t]{8}{*}{ Description $\left(n=288^{*}\right)$} & Older person & $21 \%(59)$ \\
\hline & Dementia / memory loss & $19 \%(54)$ \\
\hline & Learning disability & $7 \%(21)$ \\
\hline & Mental health needs & $7 \%(21)$ \\
\hline & Physical disability & $16 \%(46)$ \\
\hline & Long-term health condition & $18 \%(51)$ \\
\hline & Sensory disability & $9 \%(26)$ \\
\hline & Other & $3 \%(10)$ \\
\hline \multirow[t]{6}{*}{ Residence $(n=128)$} & Own home (live alone) & $48 \%(61)$ \\
\hline & $\begin{array}{l}\text { Own home (lives with } \\
\text { others) }\end{array}$ & $19 \%(24)$ \\
\hline & Care home & $12 \%(16)$ \\
\hline & Sheltered housing & $5 \%(6)$ \\
\hline & NHS inpatient unit & $1 \%(2)$ \\
\hline & Other & $15 \%(19)$ \\
\hline
\end{tabular}

* Participants selected more than one box 
Table 3 - Range of travel times (from carer's home to the person they support)

\begin{tabular}{|l|l|}
\hline Travel time & Respondent No / \% \\
\hline $1-2$ hours & $52(40.6 \%)$ \\
\hline $2-3$ hours & $25(19.5 \%)$ \\
\hline $3-4$ hours & $17(13.3 \%)$ \\
\hline $4-5$ hours & $16(12.5 \%)$ \\
\hline 5 hours+ & $15(11.7 \%)$ \\
\hline $10+$ hours & $3(2.3 \%)$ \\
\hline
\end{tabular}


Table 4 - Themes and Subthemes

\begin{tabular}{|c|c|}
\hline Theme & Subtheme \\
\hline A multiplicity of roles & \\
\hline Challenges imposed by distance & $\begin{array}{l}\text { - 'You can't just pop in' } \\
\text { - Bridging the distance gap } \\
\text { - Location }\end{array}$ \\
\hline Impacts of distance on carers & $\begin{array}{l}\text { - } \text { Emotional demands } \\
\text { - Financial demands } \\
\text { - Temporal demands }\end{array}$ \\
\hline $\begin{array}{l}\text { Strategies that support distance } \\
\text { carers }\end{array}$ & $\begin{array}{l}\text { - The use of technologies } \\
\text { - Being part of a care network } \\
\text { - } \text { Relocation }\end{array}$ \\
\hline Rewards and satisfactions & \\
\hline
\end{tabular}


Table $\mathbf{5}$ - Key roles undertaken by distance carers

\begin{tabular}{|l|l|}
\hline Type of care provided & Examples identified \\
\hline Caring for their relative/friend & $\begin{array}{l}\text { Providing personal care; providing and preparing food; } \\
\text { emotional support; supporting with appointments } \\
\text { (arranging and accompanying to appointments); } \\
\text { providing prompts and reminders; ensuring the person's } \\
\text { safety. }\end{array}$ \\
\hline Spending time with their & $\begin{array}{l}\text { Spending time together; going out on trips; keeping in } \\
\text { touch with family and friends. }\end{array}$ \\
\hline Providing practical support & $\begin{array}{l}\text { Housework and household repairs; gardening; providing } \\
\text { support with finances (including holding Power of } \\
\text { Attorney); dealing with equipment, adaptations and } \\
\text { computers. }\end{array}$ \\
\hline Acting as a care manager & $\begin{array}{l}\text { Liaising with health and social care providers; navigating } \\
\text { the care system; organising, arranging and managing }\end{array}$ \\
care; care planning; monitoring care provided.
\end{tabular}

